\title{
Metabolic Syndrome and Diabetes Type 2 in Patients Cared for at a Nutrition Out-patient Facility in the City of Rio de Janeiro, RJ
}

Patrícia Passos Simões ${ }^{1,2 *}$, Cristiane Barbosa Chagas ${ }^{2,3}$, Viviane Monteiro Dias ${ }^{2}$, Juliana Pandini Castelpoggi², Renan Moritz Varnier Rodrigues de Almeida ${ }^{4}$ and Rosângela Peluso de Campos Furtado ${ }^{5}$

${ }^{1}$ Municipal Health and Civil Defense Secretary of Rio de Janeiro/ RJ, Brazil

${ }^{2} \mathrm{Navy}$ of Brazil, Brazil

${ }^{3}$ Municipal Health Secretary of Itaguaí/RJ, Brazil

${ }^{4}$ Programa de Engenharia Biomédica - COPPE/UFRJ, Brazil

${ }^{5}$ Head of the Nutrition and Dietetics Service of the Hospital Naval Marcilio Dias, Brazil

\begin{abstract}
Background: Metabolic syndrome (MetS) is a complex disorder with a worldwide increasing prevalence. Most patients with Diabetes Mellitus type 2 (DM2) present MetS components such as overweigh/obesity, hypertension, dyslipidemia and hyperinsulinemia. However, population-based data, and more specifically Brazilian data on the subject are scarce, thus creating an interest in characterizing MetS factors in DM2 patients. Therefore, the objective of the present study was to describe the profile of diabetes mellitus type 2 patients (DM2) and to identify the presence of metabolic syndrome in this group.
\end{abstract}

Methods: Information was collected from the medical records of 127 patients who had a diagnostic of DM2 for at least two year. Biochemical (cholesterol, HDL, LDL, triglycerides, glucose, A1c, urea, creatinine and uric acid) and anthropometrical (weight, height and BMI) parameters and blood pressure were obtained. Patients were classified relatively to the presence of MetS.

Results: Dyslipidemia was present in $42.5 \%$ of the patients $(n=54)$. When evaluating the BMI, mean value was $29.7 \mathrm{Kg} / \mathrm{m}^{2}( \pm 5.9)$. Mean and standard deviation values of fasting glucose were above normal $(125.2 \pm 45.4 \mathrm{mg} / \mathrm{dL})$ and for LDL $101.6 \pm 40,1 \mathrm{mg} / \mathrm{dL}$. In the studied population, the prevalence of MetS was approximately $32 \%$.

Conclusion: Poor glycemic control, hypertension and overweight were highly prevalent in the studied population Better preventive measures are urgently needed for their control.

Keywords: Diabetes mellitus; Metabolic syndrome; Body mass index

\section{Introduction}

According to the World Health Organization (WHO) [1], there are over 220 million people with Diabetes Mellitus (DM) in the world, while in 2000 this number was 177 million Projections indicate that, in 2025, its prevalence will reach 350 million. The number of deaths attributed to DM is 800 thousand, but often DM is not mentioned in death certificates, and the complications derived from it, especially cardiovascular (CVD) and cerebrovascular diseases, are the attributed causes of death [1]. Furthermore, the estimation of Diabetes Mellitus type 2 (DM2) incidences in large populations is complicated by the need of long-term follow-ups and periodic blood glucose measurements. DM2 may appear at any age, but it is usually diagnosed in adults over 40 years old, and most patients with this type of diabetes also present overweight/obesity, with relatively few cases of single diabetes presentation [2].

In Brazil, 2006 data indicate the existence of six million DM patients, and 2013 data already point to a prevalence of about 12.5 million people [3]. Population growth and aging, higher urbanization, increasing prevalence of obesity and sedentary lifestyles (as well as a longer survival of DM patients) are the causes usually mentioned for this increase. Therefore, characterizing these patients is an important public health task, to allow for a more solid basis for resource planning and allocating in health interventions.

The metabolic syndrome (MetS) is known to be associated with a higher risk of DM complications. This syndrome is associated with CVD through factors such as centripetal obesity, visceral fat, hypertension, dyslipidemia, small, dense LDL and high levels of plasminogen activator inhibitor (PAI-1) [4,5], and the association increases cardiovascular mortality by a factor of approximately 2.5 [6,7]. Due to the frequency of MetS among patients with DM, its early diagnosis is important for the definition of an adequate therapy, allowing for the reduction of MetS complication risks. It is well known that MetS increases with age, but its distribution according to gender is still not agreed upon, with some studies pointing to a higher MetS prevalence among women, while others state that the condition would be more common among men [8-11].

Given the mentioned association between DM2 and overweight/ obesity, anthropometric evaluations are important tools for defining clinical/nutritional DM therapies, helping both the survival and the increase of a patients' quality of life [12]. To this end, the estimation of the Body Mass Index (BMI) is usually considered as the preferred method, given that BMI estimation is simple, reliable and more

*Corresponding author: Patrícia Passos Simões, Rua Scylla Souza Ribeiro, n 57/ apt. 102/ Bloco 4/ Itaipú, Niterói, RJ, 24210 510, Brazil, Tel: 552139037130 / 9218 5696; E-mail: passos ps@yahoo.com.br

Received May 03, 2013; Accepted June 18, 2013; Published June 25, 2013

Citation: Simões PP, Chagas CB, Dias VM, Castelpoggi JP, Rodrigues de Almeida RMV, et al. (2013) Metabolic Syndrome and Diabetes Type 2 in Patients Cared for at a Nutrition Out-patient Facility in the City of Rio de Janeiro, RJ. J Diabetes Metab S13: 005. doi:10.4172/2155-6156.S13-005

Copyright: (c) 2013 Simões PP, et al. This is an open-access article distributed under the terms of the Creative Commons Attribution License, which permits unrestricted use, distribution, and reproduction in any medium, provided the original author and source are credited. 
Citation: Simões PP, Chagas CB, Dias VM, Castelpoggi JP, Rodrigues de Almeida RMV, et al. (2013) Metabolic Syndrome and Diabetes Type 2 in Patients Cared for at a Nutrition Out-patient Facility in the City of Rio de Janeiro, RJ. J Diabetes Metab S13: 005. doi:10.4172/2155-6156. S13-005

reproducible than the sometimes-suggested waist circumference measurements [5].

The present study aimed to characterize the profile of DM2 patients cared for in an outpatient facility belonging to a tertiary hospital of high complexity in Rio de Janeiro, Brazil. MetS prevalence and the association between the variables gender and MetS were also investigated.

\section{Methods}

Information was retrospectively obtained from the medical records of 127 patients of both genders in a nutrition outpatient facility belonging to a high-complexity tertiary hospital in the city of Rio de Janeiro, Brazil, January - July 2011. Patients comprised enlisted military personnel and their spouses, and represented all levels of income and education. Participants had been previously (at least two years) diagnosed with DM2 according to the ADA criteria [13]. The Research Ethics Committee (Internal Review Board) of the Hospital Naval Marcílio Dias under registration No. 0023.0.221.000-11 approved the study.

Participants underwent blood tests after 12 hours of fasting and the following biochemical parameters with their respective reference values were studied: total cholesterol $(\mathrm{TC} /<200 \mathrm{mg} / \mathrm{dL})$, high lipoprotein (HDL/male: $>40 \mathrm{mg} / \mathrm{dL}$ and female: $>50 \mathrm{mg} / \mathrm{dL}$ ), low density lipoprotein ( $\mathrm{LDL} /<100 \mathrm{mg} / \mathrm{dL}$ ), triglycerides $(\mathrm{TG} / 150 \mathrm{mg} / \mathrm{dL}$ ), fasting glucose $(\mathrm{FBG} /<100 \mathrm{mg} / \mathrm{dL})$, glycated hemoglobin $(\mathrm{A} 1 \mathrm{c} /<7 \%)$, urea (UR/15 to $38 \mathrm{mg} / \mathrm{dL})$, creatinine (CR/male: 0.8 to 1.5 and female: 0.7 to $1.2 \mathrm{mg} / \mathrm{dL}$ ) and uric acid (UA/male: 3.5 to 8.5 and female: 2.5 to 6.2). The dry chemistry method was used to measure total cholesterol, HDL- cholesterol and triglycerides. The amount of LDL was calculated by the Fridewald formula [14] for individuals with triglyceride $<400$ ml. Glycated hemoglobin was obtained by the High Performance Liquid Chromatography (HPLC) method. Plasma glucose, creatinine, urea and uric acid were measured by the selective electrode method.

Anthropometric data (height and weight) were used to estimate the patient's Body Mass Index (BMI): their weight (in $\mathrm{kg}$ ) divided by the square of their height (in meters). Weight was obtained by a Filizola ${ }^{\circ}$ scale, graduated in $0.1 \mathrm{~kg}$ and with maximum capacity of $150 \mathrm{~kg}$. For height measurements, a stadiometer with a $0.5 \mathrm{~cm}$ graduation was used, and patients were measured while standing barefoot in orthostatic position. For adults below 60 years old, the following reference values and cut-off points were used: $<18.5 \mathrm{Kg} / \mathrm{m}^{2}$ (low weight (LW)), 18.5 to $24.9 \mathrm{Kg} / \mathrm{m}^{2}$ (eutrophy (EUT)), $>24.9$ to $29.9 \mathrm{Kg} / \mathrm{m}^{2}$ (overweight (OW)) and $>29.9$ (obesity (OB)). For subjects above 60 years old, these values were: $<22.1 \mathrm{Kg} / \mathrm{m}^{2}$ (underweight), 22.1 to $26.9 \mathrm{Kg} / \mathrm{m}^{2}$ (eutrophy), $>27$ $\mathrm{Kg} / \mathrm{m}^{2}$ (overweight) $[15,16]$. Patients' systemic blood pressure (BP) was measured with a mercury column sphygmomanometer standardized and calibrated after five minutes of rest.

MetS was diagnosed following the I Brazilian Guideline of Diagnosis and Treatment of the Metabolic Syndrome [7], which defines Metabolic Syndrome when three of the five following criteria are present:

- Arterial hypertension - systolic blood pressure $\geq 130$ and/or diastolic blood pressure $\geq 85 \mathrm{mmHg}$;

- Altered glucose (glucose $\geq 110 \mathrm{mg} / \mathrm{dl}$ ) or diagnosis of Diabetes;

- Triglycerides $>150 \mathrm{mg} / \mathrm{dl}$;

- HDL cholesterol $<40 \mathrm{mg} / \mathrm{dl}$ in men and $<50 \mathrm{mg} / \mathrm{dl}$ in women
Data were analyzed using the SPSS software version 19.0. At first, a descriptive analysis was performed, after what a Pearson Chi-square statistic was used for assessing the association between the dichotomous variables gender (male/female) and MetS (presence/absence) The statistical significance level was defined as $\alpha=5 \%$.

\section{Results}

The analyzed data comprised 127 patients, 65 males (51.2\%) and 62 females $(48.8 \%)$. Mean age was $64.8+11.3$ years, and frequencies according to age range were: $>30-<45$ : eight patients; $>45-<60: 29$; $>60-<75: 70$ and above $>75: 20$ patients. Dyslipidemia was present in $42.5 \%(n=54)$ of the patients, and was more prevalent in the $60-75$ age group (48\%) and in males (52\%). Hypertension was present in $76.4 \%$ $(\mathrm{n}=97)$ patients, among which $50.5 \%$ were females and $57 \%$ were in the 60-75 age group.

The mean BMI value was $29.7 \mathrm{Kg} / \mathrm{m}^{2}( \pm 5.9), 5.5 \%(\mathrm{n}=7)$ of the patients were underweight, $27.5 \%(\mathrm{n}=35)$ were eutrophic, $55.1 \%$ $(n=70)$ overweight and $11.8 \%(n=15)$ obese. In what concerns gender distribution, the overweight proportions were $28.3 \%$ and $26.8 \%$, respectively for males and females. The most prevalent nutritional diagnosis was overweight, found in $55.4 \%(n=36)$ of males and $54.8 \%$ $(\mathrm{n}=34)$ of females, respectively (Figure 1).

The mean value for fasting blood glucose was $125.2 \pm 45.4 \mathrm{mg} / \mathrm{dL}$ with $75.6 \%(n=96)$ patients above the normal range. Males and patients 60-65 were those with the higher prevalence for this parameter. Glycated hemoglobin (A1c) was measured in 118 patients, with a mean percent of $7.97 \pm 2.0 \%$ and $45 \%(n=53)$ above normal values. In 122 patients, urea mean was $46.0 \pm 30.4 \mathrm{mg} / \mathrm{dL}$, with $52.4 \%(\mathrm{n}=64)$ patients above normal; and CR mean was $1.13 \pm 0.7 \mathrm{mg} / \mathrm{dL}$, with $13.9 \%(\mathrm{n}=17)$ above normal. Among the 105 patients screened for UA, the mean was $5.4 \pm 1.5 \mathrm{mg} / \mathrm{dL}$, and the proportion above normal was $19 \%(\mathrm{n}=20)$ (Tables 1 and 2).

Concerning the lipid profile, in 122 patients Chol had mean 177.4 $\pm 43.2 \mathrm{mg} / \mathrm{dL}$, and $23.8 \%(\mathrm{n}=29)$ of the patients were above normal. For HDL, the values were: mean $51 \pm 13.0 \mathrm{mg} / \mathrm{dL}$, below normal $33.9 \%$

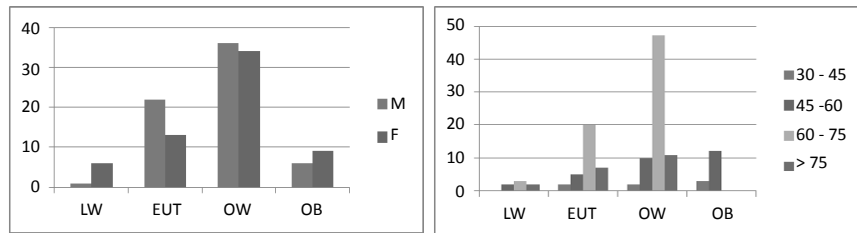

Figure 1: Anthropometric evaluation, according to gender and age group in years.

\begin{tabular}{|l|c|c|c|}
\hline Variables & $\begin{array}{c}\text { Males } \\
\text { Mean +SD }\end{array}$ & $\begin{array}{c}\text { Females } \\
\text { Mean +SD }\end{array}$ & Mean + SD \\
\hline Age & $63.1( \pm 12.6)$ & $66.5( \pm 9.5)$ & $64.8 \pm 11.3$ \\
BMI & $29.2( \pm 5.7)$ & $29.8( \pm 6.1)$ & $29.48 \pm 5.9$ \\
Uric acid & $5.4( \pm 1.3)$ & $5.4( \pm 1.6)$ & $5.43 \pm 1.5$ \\
LDL & $96.9( \pm 35.9)$ & $105.5( \pm 43.4)$ & $101.6 \pm 40.1$ \\
Urea & $46.6( \pm 33.9)$ & $45.3( \pm 26.5)$ & $46 \pm 30.4$ \\
Creatinine & $1.2( \pm 0.8)$ & $1.1( \pm 0.5)$ & $1.12 \pm 0.70$ \\
Fasting blood glucose & $131.9( \pm 53.6)$ & $118.0( \pm 33.3)$ & $125.2 \pm 45.4$ \\
Glycosylated hemoglobin & $6.9( \pm 1.5)$ & $7.3( \pm 2.5)$ & $7.04 \pm 2.0$ \\
Triglycerides & $130.9( \pm 73.2)$ & $134.4( \pm 102.3)$ & $132.6 \pm 88.1$ \\
Cholesterol & $177.7( \pm 42.5)$ & $177.2( \pm 44.31)$ & $177.4 \pm 43.2$ \\
HDL & $49.4( \pm 11.9)$ & $52.7( \pm 14.1)$ & $51.0 \pm 13.0$ \\
\hline
\end{tabular}

Table 1: Laboratory and BMI measurements, 127 patients from an outpatient facility, Rio de Janeiro, Brazil, January-July 2011. 
Citation: Simões PP, Chagas CB, Dias VM, Castelpoggi JP, Rodrigues de Almeida RMV, et al. (2013) Metabolic Syndrome and Diabetes Type 2 in Patients Cared for at a Nutrition Out-patient Facility in the City of Rio de Janeiro, RJ. J Diabetes Metab S13: 005. doi:10.4172/2155-6156. S13-005

$(\mathrm{n}=41)$; for TG, mean $132.6 \pm 88.1 \mathrm{mg} / \mathrm{dL}$, above normal $29 \%(\mathrm{n}=35)$; for LDL (118 patients), mean $101.6 \pm 40.1 \mathrm{v} \mathrm{mg} / \mathrm{dL}$, above normal $40 \%$ $(\mathrm{n}=47)$ (Tables 1 and 2).

MetS was identified in $32.3 \%(n=41)$ of the patients, $51.2 \%(n=21)$ of which were females. The 60-75 age group presented the highest prevalence $(16.5 \%, \mathrm{n}=21)$, and the syndrome was more common among overweighed patients (Table 3 ). The Chi-square test for the association gender $\mathrm{x}$ MetS yielded a $\mathrm{p}$-value $=0.71$, indicating no association between these two variables.

\section{Discussion and Conclusion}

The present study aimed to characterize the profile of DM2 patients cared for in an outpatient facility belonging to a tertiary hospital of high complexity in Rio de Janeiro, Brazil. MetS prevalence and the association between gender and the metabolic syndrome were also investigated, and the syndrome could be diagnosed in almost one out of each three participants.

Studies concerning the characteristics of DM2 patients in developing countries are very much in need, since, as discussed, the number of such patients is increasing, with a related increase in DM associated comorbidities [17]. This situation leads to early morbidity and mortality, usually at the height of the patient's productive life, placing a heavy burden on social security services and contributing to a cycle of poverty and social exclusion [3].

In this study, BMI mean values for obesity were higher among women, what agrees with epidemiological studies carried out in other regions of Brazil $[18,19]$. As mentioned, excess body weight in diabetes has been associated with a worse lipid profile and with the presence of MetS. The present study identified that more than $40 \%$ of the studied patients had a lipid profile alteration. The increase in TG and the decrease in HDL in patients with DM seem to be related to diabetic nephropathy, to cardiovascular complications and to increased mortality [1,7]. The analyzed patients also did not show an adequate glycemic control: FBG was high in more than half of the subjects. High blood glucose levels are related to serious chronic microangiopathic (diabetic retinopathy, diabetic nephropathy and distal sensory neuropathy) and macroangiopathic complications (ischemic heart disease, peripheral vascular disease and stroke) [19].

The hypertension prevalence findings of the study were shocking, since this condition was present in more than $76 \%$ of the studied population. High blood pressure is part of MetS and has a direct relationship with its other components. From a genetic standpoint, Iwai et al. demonstrated an association between the candidate genes for hypertension, hypertriglyceridemia and obesity. From a family history point of view, a study comparing children with normotensive and hypertensive parents showed that, even when normotensive, children of hypertensive parents had blood pressures, glucose and triglycerides levels higher than that of normotensive parents [20]. Another study involving children of parents with malignant hypertension [21] came to similar conclusions, indicating that normal individuals with a familial history of hypertension also exhibit hemodynamic, anthropometric and biochemical changes indicative of MetS.

Few studies tried to estimate the prevalence of MetS in the Brazilian population. A population survey in the city of Ribeirão Preto, Brazil, with adults $22-28$ years old, detected a prevalence of $7.6 \%$ for this syndrome [22]. Another population survey, made by the Ministry of Health, indicated the possibility of MetS presence in at least $14 \%$ of the adult Brazilian population, with a higher prevalence for women with low educational level, for men with excessive alcohol consumption, and for older individuals with overweight and with an insufficient level of physical activity [23].

Data from the World Health Organization (WHO) show that, for developing countries (including those of Latin America with previous malnutrition problems), obesity increased between two and three times in the last decade [15]. BMI, a common indicator for overweight assessment, requires little practice for its measurement, is inexpensive, noninvasive and has been directly associated with blood glucose levels. In a study conducted by Cabrera-Pivaral et al. [24], a decrease in BMI correlated positively with a fall in glycemia in Mexican patients with

\begin{tabular}{|c|c|c|c|c|c|c|c|c|c|c|}
\hline Variables & FBG & A1c & UR & CR & UA & Chol CT & HDL & LDL & TG & SH \\
\hline & $\mathrm{n}(\%)$ & $\mathrm{n}(\%)$ & $\mathrm{n}(\%)$ & $\mathrm{n}(\%)$ & $\mathrm{n}(\%)$ & $\mathrm{n}(\%)$ & $\mathrm{n}(\%)$ & $\mathrm{n}(\%)$ & $\mathrm{n}(\%)$ & $\mathrm{n}(\%)$ \\
\hline $\begin{array}{c}\text { Gender } \\
\text { Male }\end{array}$ & $53(55.2)$ & $28(52.8)$ & $27(42.2)$ & $10(58.8)$ & $01(5)$ & $15(51.7)$ & $14(34.1)$ & $27(57.4)$ & $19(54.3)$ & $48(49,5)$ \\
Female & $43(44.8)$ & $25(47.2)$ & $37(57.8)$ & $07(41.2)$ & $19(95)$ & $14(48.3)$ & $27(65.8)$ & $20(42.5)$ & $16(45.7)$ & $49(50,5)$ \\
\hline Age group & & & & & & & & & & \\
\hline $30-45$ & $07(7.3)$ & $04(7.50)$ & $02(3.1)$ & 0 & $01(5.0)$ & $03(10.3)$ & $03(7.3)$ & $05(10.6)$ & $02(5.7)$ & $3(3,1)$ \\
\hline $45-60$ & $25(26.0)$ & $12(22.6)$ & $10(15.6)$ & $04(23.5)$ & $05(25.0$ & $08(27.6)$ & $10(24.4)$ & $11(23.4)$ & $09(25.7)$ & $20(20,6)$ \\
\hline $60-75$ & $53(55.2)$ & $29(54.7)$ & $41(64.1)$ & $11(64.7)$ & $11(55.0)$ & $12(41.4)$ & $22(53.6)$ & $23(48.9)$ & $19(54.3)$ & $55(56,7)$ \\
\hline$>75$ & $11(11.5)$ & $08(15.1)$ & $11(17.2)$ & $02(11.8)$ & $03(15.0)$ & $06(20.7)$ & $06(14.6)$ & $08(17.0)$ & $05(14.3)$ & $19(19,6)$ \\
\hline Total & $96(100)$ & $53(100)$ & $64(100)$ & $17(100)$ & $20(100)$ & $29(100)$ & $41(100)$ & $47(100)$ & $35(100)$ & $97(100)$ \\
\hline
\end{tabular}

FBG: Fasting Glucose; A1C: Glycated Hemoglobin; UR: Urea; CR: Creatinine; UA: Uric Acid; Chol CT: Cholesterol; HDL: High Lipoprotein; LDL: Low Density Lipoprotein TG: Triglycerides; SH: Systemic Hypertension

Table 2: Distribution of biochemical parameters and arterial hypertension in 127 patients treated in an outpatient nutritional facility, Rio de Janeiro, Brazil; according to gender and age group.

\begin{tabular}{|c|c|c|c|c|}
\hline Variables & Low Weight & Eutrophic & Overweight & Obesity \\
\hline & $\mathrm{n}(\%)$ & $\mathrm{n}(\%)$ & $\mathrm{n}(\%)$ & $44(34.6)$ \\
\hline Absence of MetS & $6(4.7)$ & $26(20.5)$ & $\mathbf{n}(\%)$ & $10(7.9)$ \\
\hline Presence of MetS & $1(8.0)$ & $9(7.1)$ & $26(20.5)$ & $5(3.9)$ \\
\hline Total & $7(5.5)$ & $35(27.6)$ & $70(55.1)$ & $15(11.8)$ \\
\hline
\end{tabular}

For adults: Low weight: $<18.5 \mathrm{Kg} / \mathrm{m}^{2}$; Eutrophy: 18.5 to $24.9 \mathrm{Kg} / \mathrm{m}^{2}$; Overweight: $>24.9$ to $29.9 \mathrm{Kg} / \mathrm{m}^{2}$; Obesity: $>29.9$. For subjects above 60 years old: Low weight: $<22.1$ $\mathrm{Kg} / \mathrm{m}^{2}$; Eutrophy: 22.1 to $26.9 \mathrm{Kg} / \mathrm{m}^{2}$; Overweight: $>27 \mathrm{Kg} / \mathrm{m}^{2}$

Table 3: MetS distribution according to the BMI ranges, 127 patients from an outpatient facility, Rio de Janeiro, Brazil, January-July 2011. 
Citation: Simões PP, Chagas CB, Dias VM, Castelpoggi JP, Rodrigues de Almeida RMV, et al. (2013) Metabolic Syndrome and Diabetes Type 2 in Patients Cared for at a Nutrition Out-patient Facility in the City of Rio de Janeiro, RJ. J Diabetes Metab S13: 005. doi:10.4172/2155-6156. S13-005

DM2 that went through an educational programme. BMI was also a good predictor of both cardiovascular risk and MetS in many other studies [5].

The present study suggested the absence of an association between MetS and gender among DM2 patients. Increased glucose levels were present in most patients, indicating the need for more effective measures of glycemic control, and the same can be said regarding other risk factors for early mortality, such as hypertension and dyslipidemia. These findings are especially important, given that the studied patients were already monitored and aware of their DM2 status. DM2 population-based studies for the Brazilian population are also much in need, thus contributing to the more effective planning of health policy interventions. It should also be said that the detection of MetS involves easy-to-obtain measures, such as BMI, basic laboratory tests and blood pressure, so that there is no excuse for the absence of early diagnosis and therapy for this condition, what could minimize risks associated with the syndrome.

\section{References}

1. World Health Organization (WHO) (2012) Descriptive Note n. 312. Diabetes World Health Organization, New York.

2. Brazilian Society of Diabetes (2007) Guidelines of the Brazilian Society of Diabetes [In Portuguese], Brazilian Society of Diabetes, Rio de Janeiro 2007.

3. Ministry of Health of Brazil (2006) Primary Care Reports no 15(A): Systemic arterial hypertension [In Portuguese]. Ministry of Health, Brasília: 2006.

4. Alberti KG, Zimmet P, Shaw J (2006) Metabolic syndrome--a new world-wide definition. A Consensus Statement from the International Diabetes Federation. Diabet Med 23: 469-480.

5. de Castro SH, de Mato HJ, Gomes MB (2006) Anthropometric parameters and metabolic syndrome in type 2 diabetes. Arq Bras Endocrinol Metabol 50: 450455.

6. Chew GT, Gan SK, Watts GF (2006) Revisiting the metabolic syndrome. Med J Aust 185: 445-449.

7. Brazilian cardiology Society (2005) I Brazilian Guidelines for the Diagnosis and Treatment of Metabolic Syndrome [In Portuguese]. Arq Bras Cardiol 84: 1-20.

8. Nakazone MA, Pinheiro A, Braile MC, Pinhel MA, de Sousa GF, et al. (2007) [Prevalence of metabolic syndrome using NCEP-ATPIII and IDF definitions in Brazilian individuals]. Rev Assoc Med Bras 53: 407-413.

9. Salaroli LB, Barbosa GC, Mill JG, Molina MC (2007) Prevalence of metabolic syndrome in population-based study, Vitória, ES-Brazil. Arq Bras Endocrinol Metabol 51: 1143-1152.
10. Rigo JC, Vieira JL, Dalacorte RR, Reichert CL (2009) Prevalence of metabolic syndrome in an elderly community: comparison between three diagnostic methods. Arq Bras Cardiol 93: 85-91.

11. Figueiredo Neto JA, Figuerêdo ED, Barbosa JB, Barbosa Fde F, et al. (2010) Metabolic syndrome and menopause: cross-sectional study in gynecology clinic. Arq Bras Cardiol 95: 339-345

12. Costa AA, Neto, JSA (2004) Diabetes Manual: education, food, medications physical activities [In Portuguese]. São Paulo: Sarver, 2004.

13. American Diabetes Association (ADA) (2003) Expert Committee on the Diagnosis and Classification of Diabetes Mellitus. Diabetes Care 26: S5-20S.

14. de Souza LJ, Souto Filho JT, de Souza TF, Reis AF, Gicovate Neto C, et al (2003) Prevalence of dyslipidemia and risk factors in Campos dos Goytacazes in the Brazilian state of Rio de Janeiro. Arq Bras Cardiol 81: 249-264.

15. World Health Organization. Food and Agriculture Organization (2003) Diet, Nutrition and Prevention of Chronic Diseases. WHO Technical Report Series. World Health Organization Geneva.

16. Ministry of Health of Brazil (2004) Technical Standards for Nutrition Monitoring [In Portuguese]. Ministry of Health, Brasília.

17. Vasques AC, Pereira PF, Gomide RM, Batista MC, Campos MT, et al. (2007) Influence of body weight excess and central adiposity in glycemic and lipid profile in patients with type 2 diabetes mellitus. Arq Bras Endocrinol Metabo 51: 1516-1521.

18. Gomes MB, Giannella Neto D, Mendonça Ed, Tambascia MA, Fonseca RM et al. (2006) Nationwide multicenter study on the prevalence of overweight and obesity in type 2 diabetes mellitus in the Brazilian population. Arq Bras Endocrinol Metabol 50: 136-144.

19. Batista MCR, Priore SE, Rosado LEFPL, Tinôco ALA (2005) SCC Franceschini. Evaluating the results of multiprofessional health care on the glucemic control lipid profile, and nutritional status of diabetic patients assisted at primary leve [In Portuguese]. Rev Nutr 18: 219-228.

20. Iwai N, Katsuya T, Mannami T, Higaki J, Ogihara T, et al. (2002) Association between SAH, an acyl-CoA synthetase gene, and hypertriglyceridemia obesity, and hypertension. Circulation 105: 41-47.

21. Lopes HF, Bortolotto LA, Szlejf C, Kamitsuji CS, Krieger EM (2001) Hemodynamic and metabolic profile in offspring of malignant hypertensive parents. Hypertension 38: 616-620.

22. Bustos $P$, da Silva AA, Amigo H, Bettiol H, Barbieri MA (2007) Metabolic syndrome in young adults from two socioeconomic Latin American settings. Nutr Metab Cardiovasc Dis 17: 581-589.

23. Sá NN, Moura EC (2010) Factors associated with the burden of metabolic syndrome diseases among Brazilian adults. Cad Saude Publica 26: 1853-1862.

24. Cabrera-Pivaral CE, González-Pérez G, Vega-López MG, Arias-Merino ED (2004) Impact of participatory education on body mass index and blood glucose in obese type-2 diabetics. Cad Saude Publica 20: 275-281.
This article was originally published in a special issue, Type 2 Diabetes Mellitus- Disease, Diagnosis \& Treatment handled by Editors. Dr. Judit Bene, University of Pécs, Hungary; Eun Seok Kang, Yonsei University College of Medicine, Korea 